\title{
Metodologias Pedagógicas Ativas na Educação em Saúde
}

\author{
Maria Nizete Tavares Alves ${ }^{1}$; Miguel Marx²; Martha Maria Macedo Bezerra ${ }^{3}$; José Marcondes Macêdo Landim ${ }^{4}$
}

Resumo: A educação superior em saúde vem atravessando profundas mudanças, como forma de acompanhar as novas correntes de pensamento, sobre a formação do profissional e dos docentes. As novas tendências pedagógicas tendem para a necessidade de formar profissionais mais críticos, inteirados da realidade e, capazes de transformar seu meio social, numa realidade com mais qualidade de vida. Este manuscrito discute as metodologias didáticas ativas, mais especificamente a problematização, como possibilidade para melhorar a realidade social à partir de ações reais no contexto social dos estudantes, futuros profissionais. Trata-se de uma ferramenta que parece possibilitar uma maior consciência coletiva, necessária a um repensar de suas próprias práticas profissionais e valores sociais.

Palavras-chave: Problematização. Metodologias ativas. Aprendizagem.

\section{Pedagogical Methodologies Active in Health Education}

\begin{abstract}
Higher education in health has been undergoing profound changes, as a way of accompanying the new currents of thought, on the training of professionals and teachers. The new pedagogical trends tend towards the need to train professionals who are more critical, aware of reality and capable of transforming their social environment into a reality with a better quality of life. This manuscript discusses active didactic methodologies, more specifically problematization, as a possibility to improve social reality based on real actions in the social context of students, future professionals. It is a tool that seems to enable a greater collective awareness, necessary for a rethinking of their own professional practices and social values.
\end{abstract}

Keywords: Questioning. Active methodologies. Learning.

\footnotetext{
1 - Professora Assistente da Universidade Regional do Cariri - URCA. Curso de Enfermagem. Enfermeira da Secretária de Saúde de Juazeiro do Norte. Doutoranda em Ciências da Saúde na Faculdade de Medicina do ABC;

${ }^{2}$ Médico Perito Federal, Servidor da Universidade Federal do Cariri, Médico do Trabalho do Hospital Regional do Cariri, mestrado em terapia intensiva. E-mail: miguel.marx@ufca.edu.br;

${ }^{3}$ Mestrado em Educação pela Universidade Estadual do Ceará. Pedagoga pela Universidade Regional do Cariri, Especialização em Língua Portuguesa pela Universidade Estadual do Ceará, Especialização em Políticas Públicas pela Universidade Regional do Cariri, Especialização em Saude Mental e Psiquiatria pela Universidade Estadual do Vale do Acaraú. Atualmente, cursa o Doutorado em Saúde Coletiva pela Faculdade de Medicina do ABC. Professora concursada da Secretaria de Educação do Estado do Ceará e Professora da Rede Municipal de Juazeiro do Norte, CE. E-mail: marthamacedo2016@gmail.com

4 Mestre em Planejamento e Políticas Públicas pela UECE. Licenciado em Ciências Biológicas pela Universidade Regional do Cariri, Especialista em Botania, pela URCA, Gestão Escolar pela UDESC e Educação de Jovens e Adultos pela FJN. Ex-Secretario Municipal de Educação da Prefeitura Municipal de Barbalha (2006 a 2008). Atualmente é Professor Assistente e Diretor Geral da Faculdade de Juazeiro do Norte, Presidente do Conselho Municipal de Educação de Juazeiro do Norte e Professor rede pública Estadual do Ceará.
} 
Id on Line Revista Multidisciplinar e de Psicologia

Id on Line Multidisciplinary and Psycology Journal

\section{Introdução}

A educação superior em cursos das áreas relacionadas a saúde, vem passando por transformações para acompanhar, as concepções teóricas que norteiam a formação dos profissionais e dos docentes. Dessa forma, o modelo de ensino tradicional tem sido, gradativamente modificado, incorporando novas estratégias pedagógicas, as quais permitem a formação de um profissional mais crítico e reflexivo. Este profissional deverá ser capaz de transformar sua realidade social, mais especificamente o contexto cotidiano, visando minimizar injustiças e desigualdades.

A formação do profissional de saúde deve conduzir para efetivo compromisso com a clientela, para melhorar sua qualidade de vida e saúde, como preceitua o Sistema Único de Saúde - SUS (RODRIGUES; ZAGONEL; MANTOVANI, 2007).

$\mathrm{Na}$ docência, os profissionais da área da saúde precisam compreender as novas tendências pedagógicas e filosóficas, como ferramentas capazes de melhorar sua prática docente, quando da utilização dos recursos metodológicos alinhados às novas concepções em educação.

Sabedores somos de que as concepções sobre as práticas educativas, são orientadas pelas tendências pedagógicas, ou melhor, pela forma como é compreendido o processo de ensinoaprendizagem. Tais tendências referem-se à maneira de conduzir o processo educativo, e classificam-se como pedagogia tradicional, pedagogia renovada, pedagogia por condicionamento e pedagogia crítica (PEREIRA, 2003).

\section{Pedagogia tradicional}

Nesta linha de pensamento, as ações de ensino, geralmente são centradas no professor, que transmite o conhecimento ao aluno. Este é o único responsável pelo processo educacional. Uma autoridade quanto às estratégias de ensino a serem utilizadas. As novas tendências pedagógicas, apontam para uma pedagogia mais crítica, onde o professor assume tem o papel de mediador, conduzindo os alunos à uma mais acurada observação da realidade, visando uma 
Id on Line Revista Multidisciplinar e de Psicologia

Id on Line Multidisciplinary and Psycology Journal

transformação social, política e econômica para superação das dificuldades e minimização das desigualdades sociais (PEREIRA, 2003).

Neste contexto de novas tendências pedagógicas, as Metodologias Ativas são estratégias, onde o aluno aparece como protagonista principal. O professor, nestes casos, apresenta-se como um facilitador das experiências vivenciadas no processo de aprendizagem ${ }^{3}$.

A utilização de Metodologias Ativas parece ser ainda é um desafio para os docentes. É necessário uma mudança de paradigma, além de muito investimento em uma formação específica apropriada, para que exerçam uma práxis criadora, que possibilite a formação de sujeitos críticos e reflexivos (REIBNITZ; PRADO, 2006). Sua utilização vai implicar, não somente em conhecer os modos pare operacionalização, mas basicamente os próprios princípios pedagógicos norteadores da pedagogia crítica.

A pedagogia crítica tem como representação maior, os trabalhos do educador Paulo Freire. Suas ideias e fundamentos, tem influenciado inúmeras experiências pedagógicas em saúde, seja na educação profissional, seja na educação em saúde. Paulo Freire acreditava que, o aluno como protagonista de sua aprendizagem, apresenta maior motivação, cabendo ao professor, a tarefa de despertar sua curiosidade.

Duas formas fundamentais de utilização de metodologias ativas na saúde são a Problematização e Aprendizagem Baseada em Problemas. No primeiro caso, trata-se de uma estratégia utilizada em situações, onde os temas estão diretamente relacionados com a vida cotidiana. Tem como referência, um importante Método: o Arco de Charles Maguerez, que foi apresentado pela primeira vez, em 1982, por Bordenave e Pereira (REIBNITZ; PRADO, 2006). É um caminho metodológico que orienta a prática pedagógica do professor, quando este encontra-se verdadeiramente preocupado com o desenvolvimento e autonomia intelectual e política dos seus (BERBEL, 1998). No caso da Aprendizagem Baseada em Problemas, as situações são preparadas, previamente, de acordo com os conteúdos que os alunos precisam dominar. Cada temática deve discutir um problema, geralmente em pequenos grupos (BERBEL, 1998). No Brasil, em uma retrospectiva histórica da aplicação de Metodologias Ativas, identificou-se ser o seu uso recente na educação formal, mais precisamente, a partir dos anos 2000, como forma de formar profissionais de saúde para o Sistema Único de Saúde (SUS).

Dessa forma, várias ações foram necessárias, dentre as quais, a implementação do Programa Aprender SUS, a efetivação de uma Política Nacional de Educação Permanente para 
Id on Line Revista Multidisciplinar e de Psicologia

Id on Line Multidisciplinary and Psycology Journal

trabalhadores do SUS e, o desenvolvimento do Programa Nacional de Reorientação da Formação Profissional em Saúde, o Pró-Saúde (RODRIGUES; CALDEIRA, 2008).

O presente estudo objetiva discutir aspectos das Metodologias Ativas em cursos de saúde e sua importância estratégica, enquanto metodologia pedagógica inovadora.

\section{Ensinar Aprendendo}

Apreender e dominar acerca do tema Metodologias Ativas, no contexto acadêmico, parece sempre um desafio ao educador. Até porque é necessário toda uma coerência entre o discurso e a prática adotada.

Portanto, neste caso, o professor se coloca como um facilitador da disciplina (e não como um professor, tal como no modelo tradicional de ensinar). Os alunos é que serão os protagonistas neste processo. É do professor-facilitador, a responsabilidade na condução da turma, para a vivência e compreensão da Metodologia Ativa.

A fundamentação teórica para a metodologia da Problematização, parece ter origem na concepção da educação histórico-crítica. O propósito maior foi o de preparar o estudante, para tomadas de consciência da sua realidade, frente ao mundo e, atuar de forma mais intencional e consciente para transformá-lo (BERBEL, 1999).

O Arco de Charles Maguerez, é uma estratégias educacionais possível para o desenvolvimento da Problematização. Este consta de cinco momentos: 1) a observação da realidade, 2) percepção dos pontos-chaves, 3) teorização, 4) hipóteses para solução do problema e, 5) aplicação à realidade. As mesmas estão descritas na sequência ${ }^{7}$.

\section{1) A observação da realidade}

Esta primeira etapa constitui-se da Observação da Realidade social, pelos alunos, partindo-se sempre de um tema ou unidade de estudo. Neste caso, os alunos tentarão um olhar mais atento para a sua realidade, para registrar de maneira sistemática, o que perceberam sobre a realidade, dentro do tema trabalhado. Tal observação vai permitir aos alunos, a identificação 
Id on Line Revista Multidisciplinar e de Psicologia

Id on Line Multidisciplinary and Psycology Journal

de possíveis dificuldades ou carências, de variadas ordens, que serão dispostas em forma de problemas. Um dos problemas deverá ser eleito, para que se possa trabalhar com todo o grupo. Outra opção é que vários problemas sejam trabalhados em pequenos grupos. As discussões serão posteriormente socializadas, em um momento com a presença do professor, onde eleborar-se-á uma síntese das discussões.

\section{2) Percepção dos pontos-chaves}

Nesta segunda fase, os alunos irão refletir mais um pouco acerca dos Pontos-Chaves, propostos na primeira fase. Serão levantadas hipóteses sobre as possíveis causas e/ou consequências da existência do problema em estudo. A questão principal para reflexão é: Por que será que esse problema acontece?

Assim, com as informações disponíveis e conhecimentos prévios sobre a questão, passam a discutir os problemas sob as mais variadas dimensões (social, educacional, econômica, cultural, dentre outras). Aprendem que um problema é complexo e multideterminado. Continua-se as reflexões, e os alunos são estimulados a realizarem uma nova síntese: Elabora-se pontos mais essenciais sobre o problema, compreendendo em maior profundamente, para poder encontrar formas de intervenção na realidade. São pensados os passos na direção de uma solução.

\section{3) A Teorização}

Nesta terceira fase, é o momento do estudo, propriamente dito. Os alunos devem buscar informações coerentes e de fontes confiáveis, para definirem melhor o problema e suas nuances. Utilizarão para isso a biblioteca, as revistas especializadas, jornais, internet, periódicos, consulta a especialistas no assunto, dentre outras fontes. Podem se valer de questionários para obtenção de informações, frequentar palestras e/ou aulas. As informações que forem obtidas nesta fase, serão tratadas, analisadas e avaliadas, conforme suas contribuições para resolução do problema. Tudo deve ser registrado, para possibilitar as conclusões do grupo. 
Id on Line Revista Multidisciplinar e de Psicologia

Id on Line Multidisciplinary and Psycology Journal

\title{
4) Hipóteses para solução do problema
}

Esta é a etapa do levantamento das hipóteses que levarão a solução do problema. Todo o estudo será agora reavaliado, de forma a se elaborar possíveis soluções. Deve-se tentar responder às seguintes indagações: O que é preciso acontecer para a solução deste problema? O que precisa providenciar? O que efetivamente pode ser feito neste caso? Observe-se que, as hipóteses são construídas depois do estudo, não antes.

\section{5) Aplicação à realidade}

Esta quinta e última etapa da Metodologia da Problematização, vai além do exercício intelectual. Segundo Berbel (1999, p.8-9),

\begin{abstract}
As decisões tomadas deverão ser executadas ou encaminhadas. Nesse momento, o componente social e político está mais presente. A prática que corresponde a esta etapa implica num compromisso dos alunos com o seu meio. Do meio observaram os problemas e para o meio levarão uma resposta de seus estudos, visando transformá-lo em algum grau.
\end{abstract}

Completa-se dessa forma, o Arco de Maguerez, com o objetivo de levar os alunos ao exercício dialético da ação-reflexão-ação, tendo como ponto inicial e final de aprendizagem, a realidade social.

Em Resumo, a Metodologia da Problematização, como exemplo de uma metodologia ativa, apresenta uma orientação geral, que passa por etapas distintas na tentativa de compreensão da construção de um problema observado na realidade. Constitui-se de um conjunto de procedimentos ou atividades, que são intencionalmente propostas, para que se conheça todas as nuances do problema e das suas possíveis soluções.

Com em todo o processo, desde a observação do que seja um problema na realidade até a discussão coletiva sobre as informações e possíveis soluções, há algo extremamente importante que é a apreensão da realidade contextual pelos alunos. Tem-se como objetivo uma mobilização de todo o potencial emocional, social, ético e político dos alunos, que estudam a 
Id on Line Revista Multidisciplinar e de Psicologia

Id on Line Multidisciplinary and Psycology Journal

situação, embasados cientificamente para uma proposta de ação que seja adequada e eficaz, como cidadãos e profissionais. É uma forma de serem agentes na construção histórica de sua realidade social, mesmo que em pequena dimensão.

\section{Considerações finais}

As metodologias ativas são ferramentas didáticas inovadoras formação de um profissional crítico-reflexivo. Até porque são estes mesmos profissionais que darão continuidade a ações semelhantes na sua realidade. Para isso, faz-se necessárias capacitações docentes continuadas, no exercício da prática reflexiva, de forma a que sejam capazes de estimular no aluno o exercício das perguntas de partida. Tais procedimentos possibilitam a imersão consciente dos alunos na experiência coletiva, carregada de valores, conotações simbólicas, afetos e interesses sociais e políticos. Nesta situação, o professor precisa assumir sua posição como facilitador no processo de aprendizagem do aluno, de forma a possibilitar no aluno uma atitude investigativa perante o mundo.

A prática pedagógica deve levar em conta que os alunos possuem grande potencial criativo e realizador, contribuindo para que, como profissionais possam atuar de forma mais consciente e humana. As metodologias ativas oportunizam o resgate da valorizando do seu contexto e das características individuais, elementos com os quais o profissional de saúde precisa aprender a lidar no cotidiano laboral. As experiências vivenciadas pelas metodologias ativas, aqui demonstradas as características da problematização, representam uma proposta pedagógica de grande significado e que, certamente possibiliará aos alunos e docentes, repensar e reorganizar suas próprias práticas pedagógicas e, modos de ver suas realidades.

\section{Referências}

BERBEL, N.A.N. A problematização e a aprendizagem baseada em problemas: diferentes termos ou diferentes caminhos? Interface: comunic, saude, educ. [periódico on-line]. 1998 fev. 
Id on Line Revista Multidisciplinar e de Psicologia

Id on Line Multidisciplinary and Psycology Journal

BERBEL, N.A.N. Metodologia da problematização: fundamentos e aplicações. Londrina: Ed INP/UEL, 1999.

PEREIRA, A.L.F. As tendências pedagógicas e a prática educativa nas ciências da saúde. Cad Saude Publica. Periódico on-line. 2003, set/out.

REIBNITZ, K.S., PRADO ML. Inovação e educação em enfermagem. Florianópolis: Cidade Futura, 2006.

RODRIGUES, R.A., CALDEIRA, S. Movimentos na educação superior, no ensino em saúde e na enfermagem. Rev Bras Enferm. Periódico na internet. 2008, set/out.

RODRIGUES, J.; ZAGONEL, I.P.S.; MANTOVANI, M.F. Alternativas para a prática docente no ensino superior de enfermagem. Esc Anna Nery. Periódico on-line. 2007, jun.

Como citar este artigo (Formato ABNT):

ALVES, M.N.T,; MARX, M.; BEZERRA, M.M.M.; LANDIM, J.M.M. Metodologias Pedagógicas Ativas na Educação em Saúde. Id on Line Revista Multidisciplinar e de Psicologia, Janeiro de 2017, vol.10, n.33, Supl 2. p. 112-125. ISSN: 1981-1179.

Recebido: 03/01/2017

Aceito: 10/01/2017 